
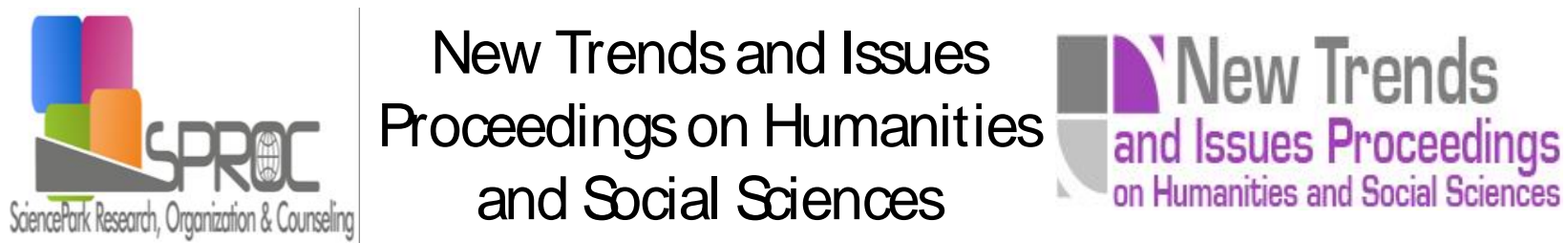

\title{
Electronic cultural programs as an educational resource
}

Baktybayev Zhanat ${ }^{\text {a } *}$

Chaklikova Assel b

Sultanova Gulfariza ${ }^{c}$

Abdeyeva Svetlana ${ }^{d}$

Akhmediyeva Kulmariya ${ }^{\mathrm{e}}$

Suggested Citation:

New Trends and Issues Proceedings on Humanities and Social Sciences.

Abstract 
New Trends and Issues Proceedings on Humanities and Social Sciences.

1. 
New Trends and Issues Proceedings on Humanities and Social Sciences. 




Figure 1. Fragments of the ECP "World Art"

\section{Conclusion}




\section{References}

Modern problems of science and elementary education

Procedia-Social and Behavioral Sciences

Introduction to the methodology and methods of pedagogical research Methodology and methods of psycho-pedagogical research 